\title{
A MUNICIPALIZAÇÃO DO ENSINO: ALGUMAS QUESTÕES SOBRE O PODER LOCAL
}

Angela Maria Martins

Universidade Católica de Santos, Brasil

\section{A POLÍTICA E SUA GESTÃO: PROCESSOS DECISÓRIOS E PODER LOCAL}

A discussão sobre democracia na literatura política invariavelmente vem acompanhada de ponderações acerca das reais possibilidades de compartilhamento do poder e da representação dos cidadãos. O tema é analisado, de um lado, por teóricos defensores da formalidade imposta pelas regras do jogo democrático, ou em outras palavras, pela defesa incondicional dos procedimentos formais de delegação da representação, com base em eleições que consagram a convivência democrática; de outro, encontram-se os defensores da conquista de ampliação de participação daqueles que se acham subrepresentados, mesmo que essa ampliação ainda represente uma defesa dos canais legitimados pela formalidade dos procedimentos democráticos. Ao longo do século $X X$, no campo da teoria política, a discussão sobre as transformações inevitáveis e inerentes às sociedades democráticas e aos seus mecanismos de funcionamento, oscila entre a defesa dos procedimentos formais de participação social e política dos indivíduos, e a constatação da complexidade da distribuição do poder nessas sociedades, isto é, sobre a necessidade de ampliação dos canais de representação.

Nas últimas décadas, a preocupação central se acha dividida entre a idéia de manter a democracia nos moldes liberais, baseada sobretudo na representação exclusivamente via eleições, ou a de ampliar seu próprio conceito, buscando nas idéias socialistas inspiração para a defesa de ampliação da participação e da representação daqueles segmentos que se acham sub-representados. De qualquer modo, a adoção de procedimentos formais como via legítima para que a democracia represente interesses heterogêneos, generalizou-se ao longo do século XX e continua sendo a forma que dá vida aos regimes democráticos, embora outros teóricos sublinhem que estes procedimentos estão longe de ser sua substância. De acordo com Santos, Avritzer (2002), a tensão entre capitalismo e democracia sobretudo nos países centrais, visando priorizar a acumulação do capital e controlar a redistribuição social na tentativa de evitar o que se denominou sobrecarga democrática, explodiu após os anos 1980. A pressão criada por segmentos sociais que nunca tiveram acesso às políticas de proteção - acrescida da pressão formulada por outros segmentos inseridos nessas políticas -, criou demandas sobre as democracias formais que buscaram respondê-las através de diferentes estratégias de governo, contaminando os países periféricos ou semi-periféricos. As estratégias adotadas para reorientar a capacidade de atendimento das democracias ocidentais às demandas crescentes, variam de acordo com as características históricas, políticas, econômicas e culturais dos países envolvidos, no entanto, de modo geral, consolidou-se a idéia de uma democracia capaz de controlar a governabilidade, em detrimento da idéia de uma democracia capaz de inserir a pluralidade contida nos segmentos excluídos, sem deixar de atender aos que já estavam assistidos.

No rastro desse debate, insere-se a defesa da desmontagem do aparelho burocrático que dá vida às sociedades democráticas ocidentais: se os problemas são heterogêneos, sua solução deve ser buscada em diferentes procedimentos e níveis administrativos da gestão da coisa pública, em contraposição às 
políticas centralizadas e burocratizadas implementadas até meados do século XX. Em escala ampliada, o exercício da democracia buscou soluções na facilidade encontrada pela representação formal. Porém, encontrou dificuldades no que diz respeito à prestação de contas e à representação das múltiplas identidades fazendo com que os choques de interesses étnicos, de opção sexual, religiosos, raciais, etc., fossem inevitáveis. $\mathrm{Na}$ contra-corrente das concepções hegemônicas - de modo geral defensoras dos procedimentos formais para autorização da representação dos cidadãos como únicos canais legítimos de prática democrática -, houve uma revalorização dos valores democráticos baseados, no entanto, em novos mecanismos de participação social e política. Uma solução apontada após os anos 1980 para que a democracia liberal se viabilize como regime hegemônico, é a ampliação da participação dos cidadãos em nível local. Supõe-se que a democracia exercida em escala menor - nas localidades - facilite a superação dos problemas colocados pelos diferentes níveis da burocracia, bem como pela complexa questão da representação. Nas cidades, por exemplo, as condições para o desenvolvimento de experiências alternativas e o exercício de práticas democráticas seriam maiores, estariam delimitadas territorialmente, se beneficiariam da proximidade do poder e seriam baseadas na criatividade dos atores locais. Esta idéia encontra respaldo nas teorias contra-hegemônicas de democracia que também defendem uma convivência e uma complementariedade entre níveis de escala dentro do regime democrático (Santos, Avritzer, 2002).

Resta uma pergunta: até que ponto ou de que maneira os novos desenhos institucionais surgidos de formas experimentais de exercício democrático, podem mudar substancialmente o modelo hegemônico de democracia? Em outras palavras, de que forma a dinâmica instaurada em função da descentralização de processos decisórios, tais como este aqui analisado, configura um novo desenho institucional para a prática da democracia em pequena escala, permitindo: aperfeiçoamento na gestão das políticas; participação efetiva dos atores escolares nas decisões coletivas; encaminhamento de soluções mais efetivas e eficazes para os graves problemas configurados pela burocratização da implementação de políticas. Ou, os novos desenhos são apenas a reconfiguração de novas práticas discursivas oficiais a partir de velhos modelos de exercício da democracia e da gestão das políticas que Ihes dão materialização?

\section{O PROCESSO GESTOR DA MUNICIPALIZAÇÃO NO ESTADO DE SÃO PAULO: UMA ANÁLISE POSSÍVEL}

Após o fim do regime militar no Brasil e a instauração de um processo de democratização política, a redistribuição das receitas públicas para dotar as subunidades federadas de maior autonomia financeira, ao que tudo indica, ainda está longe de resolver de forma satisfatória a redefinição do desenho das políticas setoriais, embora tenha iniciado um percurso de mudanças fundamentais para que o modelo de gestão de Estado centralizado seja superado. De modo geral, a indefinição de competências, a dispersão de esforços e recursos, as dificuldades para se responsabilizar as diferentes esferas executivas pela inexistência ou inadequação da prestação de serviços, têm sido as características do processo descentralizador no Brasil. De qualquer forma, a descentralização tem ocorrido baseada na redistribuição das receitas, de um lado, e de outro, fundamentada em novos arranjos político-institucionais, com a redistribuição de competências entre as diferentes esferas de governo ${ }^{1}$. Como medida última, o processo descentralizador vem

\footnotetext{
${ }^{1}$ Um dos principais mecanismos de indução à descentralização no Brasil se configurou na Emenda Constitucional n. 14 (Fundef), estabelecendo que durante 15 anos, 15\% das receitas fiscais que Estados e municípios arrecadam com transferências constitucionais e com impostos (FPE; FPM; ICMS e IPI das exportações) sejam destinados ao fundo.
} 
transferindo, gradativamente, funções do setor público para o setor privado lucrativo ou não lucrativo, com base na instauração de parcerias e convênios.

No mais rico Estado federativo brasileiro - São Paulo -, a agenda política derrapou até meados dos anos 1990 no modelo de gestão intrinsecamente ligado a mecanismos centralizadores, cuja ruptura, a partir daí, só foi possível graças à vitória do ideário que defendia um projeto de modernização administrativa, constituindo-se um campo de tensão no planejamento da educação a partir da instauração de processos descentralizadores. Dentre as principais medidas que operacionalizaram esse processo de mudanças institucionais no Estado de São Paulo, está a transferência de escolas, professores e alunos de 1 a 4 séries, aos municípios, pois historicamente, a cobertura do ensino fundamental tem sido feita pelo setor público, com especial destaque para a maciça participação da Secretaria Estadual da Educação, responsável por 79\% das matrículas nesse nível de ensino, por exemplo, em 1995. Com a redefinição de competências entre as esferas de governo a partir de 1996, intensificada nos anos seguintes, os municípios paulistas passaram a assumir a responsabilidade pelas matrículas de $1^{\text {a }}$ a $4^{\text {a }}$ série, saltando de $12 \%$ para $44 \%$ a sua participação no conjunto de matrículas, no período de 1996 a 2001; enquanto a rede estadual caía de 77\% para $44 \%^{2}$.

O desenho institucional que se formou na política educacional paulista em decorrência do convênio que transferiu professores, alunos, prédios escolares e funcionários da esfera estadual para os municípios, é fragmentado e forma um mosaico de interesses díspares, o que nos permite afirmar que a sacralizada cultura burocrático-administrativa centralizada nos anos 1970, começa a sofrer fissuras, para o bem e para o mal. Considerando-se as enormes desigualdades regionais no tamanho, formas de atendimento, desempenho e capacidade fiscal dos municípios paulistas, configura-se uma engenharia operacional de transição onde os novos papéis institucionais vêm sendo

testados de todas as formas, pois pode-se afirmar, com certa tranquilidade, que cada município é um caso. A retirada de cena da esfera executiva federal, substituída, em parte, pelas novas prerrogativas dadas aos estados e municípios para que estes passem a assumir novas competências de gestão, não constitui apenas um problema técnico, mas esbarra exatamente, na cultura política sacralizada em torno de negociações nem sempre pontuais, mas que tendem a se configurar como fisiológicas.

A cultura institucional - o sistema de crenças, valores e de interação dos atores entre si e entre estes e a própria organização -, ao ser instado a se modificar, metaforiza parte do ritual normativo, incorporando o velho, no novo desenho que se forma como estratégia de sobrevivência. Da mesma forma, o clima organizacional - as técnicas e procedimentos; a política de recursos humanos; as metas, regulamentos e estatutos; o comportamento encorajado dentro da instituição; as atividades de caráter integrador, etc. -, também sofre um processo de aprendizagem em contextos de mudança, conforme se observou na pesquisa de campo. Em contextos de mudança institucional nos quais ocorrem negociação de transferência de responsabilidades e/ou de compartilhamento de poder, pode se constituir um paradoxo. A necessidade de forjar novas formas de desempenho das políticas educacionais exige que as instituições envolvidas em sua implementação adquiram um corpo de informações e de conhecimentos burocráticoadministrativos para assumir suas novas funções, o que, sem dúvida, gera um período de tensão política e de vácuo no conjunto normativo-legal, pois sua racionalidade não responde mais às necessidades do 
cotidiano. Isto é, entre o que este conjunto propugna para que a gestão da política educacional funcione em outro paradigma, e sua efetiva operacionalização, configura-se um período de instabilidade institucional que imprime rumos inesperados æ̀ suas diretrizes, na tentativa de romper a cultura fortemente enraizada em seus órgãos gestores e nas próprias unidades escolares.

A conduta da Secretaria Municipal de Educação A foi no sentido de negociar a transferência de alunos e professores, construindo, nesse processo, o que se convencionou denominar de "condomínios", pois as escolas municipalizadas, em alguns casos, funcionavam dentro das escolas estaduais onde, durante um período de tempo, conviveram no mesmo espaço físico professores, diretores e coordenadores pedagógicos estaduais e municipais. Em outros casos, o Estado construiu o prédio e a prefeitura assumiu sua gestão. Essa situação gerou, em uma das escolas analisadas, uma relação de colaboração efetiva, onde as duas diretoras trabalharam em conjunto encaminhando e resolvendo as situações de ordem administrativa e pedagógica. Porém, essa situação de colaboração não expressa o que ocorreu em toda a rede transferida. A situação mais usual - e que gerou pólos de tensão para a Secretaria Municipal de Educação - foi o estabelecimento de uma profunda disputa entre os profissionais que pertenciam ao estado e aqueles que foram conveniados.

Na cidade B, o processo de transferência se deu através do "repasse" de escolas estaduais para a prefeitura, com base numa discussão sobre municipalização que teve início em março de 1997, envolvendo toda a rede de ensino na cidade. O principal argumento nas discussões realizadas sublinhava que o Fundef - elemento indutor desse processo -, não deixava margem de manobra para o executivo municipal. $\mathrm{Na}$ realidade, a esfera executiva estadual constitui o centro gestor centralizado do Fundo, tendo em vista que detém a maior parte do atendimento, competindo a esta esfera repartir os recursos e possibilitando-Ihe reforçar os mecanismos do que se denomina ultrapresidencialismo estadual. O município, até 1998, não assumia o ensino de primeira a quarta série, resumindo-se a gerenciar um rede de pré-escolas. No final de 1998, elaborou-se o Estatuto do Professor Municipal e em 1999 estruturou-se o Departamento de Educação. A reconhecida "falta de experiência política, burocrática e administrativa" para gerenciar volumosos recursos humanos e financeiros, sublinhada por todos os entrevistados das equipes centrais, gerou um processo tenso e até certo ponto, anômico, de mudança institucional.

De qualquer forma, apesar do processo de transferência de escolas, professores, funcionários e alunos se constituir em objeto de polêmica e estar permeado de contradições, houve consenso na concepção dos secretários de educação, membros dos conselhos municipais e diretores, ao defenderem a mudança física e simbólica do locus de negociação entre os atores escolares e o poder executivo, embora reconheçam os riscos dessa proximidade. De um lado, essa aproximação parece contemplar a reivindicação pela ampliação da participação dos atores escolares e da comunidade, pois os canais de comunicação são encurtados e os conflitos gerados nesse processo são negociados diretamente com os gestores dos sistemas municipais. De outro lado, há o risco de se reinstaurar as velhas e conhecidas fórmulas de fazer política local, pois, pelo que se pôde observar, as regras para distribuição de cargos parecem ainda não estar claras ou baseadas na racionalidade dos concursos públicos.

O desenvolvimento de estratégias e mecanismos governamentais de indução para que os municípios adiram aos programas de descentralização do governo federal - e o Fundef é um dos principais

\footnotetext{
${ }^{2}$ Na pesquisa original, os dados foram sistematizados e analisados por José Roberto Rus Perez, professor do Programa
} 
mecanismos -, não exclui o complexo processo de negociação entre as esferas federal, estadual e municipal, tendo em vista que os arranjos político-partidários originam as mais diferentes barganhas. Nesse sentido, a proximidade proporcionada pela delimitação do espaço territorial entre instâncias de atuação e níveis administrativos, parece contemplar a reivindicação pelo alargamento das bases democráticas de funcionamento da rede de escolas, de um lado. De outro, os mesmos profissionais entrevistados sublinham que essa proximidade é potencialmente perigosa, pois coloca em risco o anonimato necessário até para preservação do emprego. Os conflitos de poder, nesse sentido, são utilizados em sentido contrário daquele que alimentaria a dinamização do exercício democrático.

Os diretores de escolas, por exemplo, continuam sendo indicados em ambas as cidades. Ainda não foram instaurados concursos públicos para preenchimento dos cargos. Essa questão foi encaminhada apenas em 2002, pelos dois municípios, para tentar evitar justamente as indicações de ordem políticopartidária que vêm permeando essas indicações e/ou para evitar os trânsitos inevitáveis entre diretores e os demais profissionais alocados nos órgãos centrais das secretarias municipais de educação. Essas relações podem, muitas vezes, causar conflitos intra-muros escolares, tendo em vista a desconfiança que se estabelece entre a direção da escola e o quadro docente ${ }^{3}$. Como em todo processo de mudança institucional, está se configurando um vácuo legal-normativo, pois todas as prescrições do conjunto de orientações da Secretaria de Estado da Educação, esbarram nas peculiaridades dos municípios envolvidos, desenhadas por profundas diferenças no atendimento e na cobertura dos serviços educacionais. Vem ocorrendo uma ampliação, sem precedentes, dos encargos administrativos e pedagógicos para os municípios, tendo em vista que nas Secretarias Municipais não existia, até o presente momento, uma cultura burocrático-administrativa e financeira, pois todo o conjunto normativo era de responsabilidade restrita da esfera estadual. Na implementação do convênio, esse arcabouço - que não é pequeno - está sendo assumido pela esfera municipal, com a otimização dos Conselhos Municipais de Educação ${ }^{4}$ e/ou com a estruturação de um sistema de supervisão da rede de escolas.

Mudar as bases de negociação não é tarefa simples nem constitui um simples mecanismo burocrático. As esferas executivas vêm procurando responder às novas demandas postas para a gestão da política educacional, com diferentes estratégias de governo que variam de acordo com as características históricas, políticas, econômicas e culturais dos municípios envolvidos. Sem sombra de dúvida, a necessidade de ampliação da participação dos atores envolvidos em sua operacionalização é condição sine qua non para que os problemas - heterogêneos -, encontrem soluções também diferenciadas localizadas na gestão municipal. Dessa forma, o redesenho institucional das próprias secretarias municipais de educação - seus novos órgãos e fuxogramas - bem como os conselhos municipais, vêm configurando novas formas de gestão da política educacional

Porém, a democracia, sua prática e seus canais de expressão não se resumem a um problema de escala. Ao que tudo indica, pelas observações e entrevistas realizadas em ambos os municípios, não é de todo improvável que ocorram algumas reversões das expectativas locais, tendo em vista o legado político e a possibilidade de cooptação dos órgãos, pois a burocratização da participação dos atores é inevitável.

\footnotetext{
de Pós-Graduação da Faculdade de Educação da Unicamp, e pesquisador convidado da Fundação Carlos Chagas.

${ }^{3}$ Aos olhos dos pais entrevistados, ao contrário, o trânsito livre do diretor pelo centro de decisão - a secretaria municipal - facilita reivindicar e negociar propostas.

${ }^{4}$ No caso da cidade A, por exemplo, o Conselho Municipal de educação desempenha as funções de braço operacional da própria secretaria.
} 
Portanto, o risco de se reintroduzir outras e novas formas de manipulação dos diferentes interesses é grande, tendo em vista que fundamentalmente, os processos de negociação em sociedades democráticas ocorrem em torno de interesses corporativos, estejam eles situados em quaisquer espaços nos quais a democracia possa ser exercida. Algumas das principais questões que compõem a tensão configurada por esse jeito de fazer política, herança de um passado que se manifesta com intensidade no presente, não encontrarão solução imediata, pois a possibilidade de mudança na cultura institucional ainda não passa disto, uma possibilidade. Dentre os principais entraves ressaltem-se: a manipulação de informações por parte de segmentos que representam diferentes interesses locais; alguma indiferença e/ou desprezo em relação aos critérios estabelecidos pela nova forma de administrar; a negociação de influências e níveis de participação nas decisões de impacto da esfera executiva, do tipo: quem levará vantagem (entenda-se qual grupo) se tal medida for implementada? Sem dúvida, a (re) normatização dos conselhos locais constituídos em processos de negociação cujas bases ainda sofrem de males hereditários -, podem mudar substancialmente o modelo de gerenciamento da política educacional.

É necessário, contudo, olhar para esse processo com a devida compreensão de que ainda levará muito tempo para que a possibilidade de ampliação de participação dos atores escolares nos órgãos deliberativos locais, seja de fato o resultado de amadurecimento da democracia participativa, e não mais um mecanismo de camuflagem na defesa de interesses pouco transparentes. Questões como o legado da cultura política local; a existência ou ausência de quadros capacitados tecnicamente para assumir a gestão de vultuosos recursos financeiros; a ampliação sem precedentes dos recursos humanos envolvidos; as diferenças nos níveis de participação dos cidadãos através de canais competentes, etc., formam um caldo político-institucional neste período de transição que pode ser desastroso, de um lado, caso esse vácuo permaneça por um período de tempo insustentável para a estabilidade da gestão pública. De outro lado, esse caldo poderá gestar novas formas de relacionamento entre as esferas executivas se a aprendizagem gerada no processo conseguir dinamizar os canais de expressão locais - o que demonstraria maturidade política dos atores envolvidos -, ao invés de aprofundar as relações de mando e obediência. Só o tempo, no entanto, comprovará qual das tendências deverá prevalecer.

Outro problema grave a ser resolvido diz respeito à diferença salarial entre diretores municipais e estaduais que, nos dois casos analisados, é bastante significativa a favor dos municípios, gerando profundo constrangimento quando dois diretores são colocados no mesmo espaço, caso das escolas que viraram condomínios, pois teoricamente, ambos exercem as mesmas funções, dentro do mesmo espaço físico e recebem salários muito diferentes para isso. Embora a sensação de insegurança e de provisoriedade da situação trabalhista venha diminuindo à medida em que os executivos municipais estão aperfeiçoando sua aprendizagem institucional, estruturando departamentos, organizando fluxogramas e treinando equipes técnicas para administrar vultuosos recursos financeiros e humanos, a sensação de não saber a quem obedecer ainda é bastante forte entre os profissionais e tem fundamento no próprio vácuo constituído nesse processo de transição. As dúvidas pairam sobre questões até então comuns: faltas abonadas; férias; décimo terceiro salário; formação em serviço.

As relações entre as Diretorias de Ensino Regional e as Secretarias Municipais de Educação também estão baseadas na racionalização do atendimento das matrículas, tendo sido contornado o problema da demanda. Porém, os mesmos problemas de (re) concentração de poder local são apontados pelos entrevistados. O enxugamento das antigas Delegacias de Ensino e sua reconfiguração local em 
"cidades polo" que atendem um número grande de escolas, tem sido apontado como um grave entrave na agilidade, democratização e acesso dos profissionais da rede de escolas às informações e capacitações ministradas ${ }^{5}$. Dessa forma, o novo desenho institucional evidencia que o processo de descentralização em curso não constitui simplesmente uma etapa subsequente da descentralização financeira e fiscal, sem que sejam consideradas as peculiaridades que envolvem o complexo processo de negociação entre as esferas de governo. Nesse sentido, é inevitável que as administrações locais realizem uma leitura política sobre os possíveis ganhos e perdas resultantes do fato de assumirem (ou não) os compromissos de gestão da rede de escolas.

Em suma, o atendimento municipalizado aproxima mais os profissionais da educação, os alunos e seus pais do centro de decisão, facilitando constituir a pauta de reivindicações e localizando mais facilmente os conflitos entre estes e os gestores do sistema municipal. Porém, o processo tem sido permeado de problemas que parecem se eternizar no ensino público, pois a expansão repentina das redes municipais têm provocado, ao que tudo indica, o início de um declínio da qualidade do ensino ofertado anteriormente, evidenciando que a tensão entre a expansão da cobertura de serviços sociais e a manutenção da qualidade é realmente difícil de ser resolvida. Essa situação pode ser resumida na frase paradigmática da secretária municipal de educação da cidade A:

"Como secretária, a mim pesa mais o administrativo, porque a política municipal é próxima da população usuária, logo todas as suas atitudes são mais questionáveis....antes tudo era para educação infantil, 95\% da verba de educação no município, ia para a área infantil. De repente, tenho que otimizar os recursos de tal forma que eu possa fazer com 40\% o mesmo que eu fazia com 95\%. Algumas atitudes que nós tivemos de tomar para que houvesse uma contenção de despesas são politicamente desastrosas! Eu acho que isso é um processo histórico, só lá na frente as pessoas entenderão o que foi feito. É muito desgastante (...), vai para audiência pública na câmara, vai para televisão e rádio...”

Na história da política educacional paulista mais recente, modificou-se radicalmente a natureza das relações entre a esfera executiva estadual e os municípios, numa conjuntura, porém, nem sempre favorável para que a efetiva descentralização seja bem sucedida. Como demonstram os dados, o convênio atinge municípios de pequeno, médio e grande porte com capacidade fiscal, administrativa, perfil político-partidário e cobertura do ensino fundamental totalmente diferentes entre si, tendo construído, ao longo de sua história, mecanismos de participação da população local também diferenciados. A engenharia operacional em curso, ao desconsiderar as peculiaridades culturais, demográficas e sócio-econômicas dos municípios paulistas desenhou um mosaico fragmentado originando não apenas um processo de municipalização, mas vários.... De um lado, pode-se dizer que, finalmente, o discurso prevalecente ao longo dos anos 1980 que enfatizava a necessidade de se desmontar o aparato burocrático ineficiente e centralizado da educação paulista, foi atendido. Ninguém discorda que o exercício democrático exige atualmente uma revisão dos mecanismos de representação nas democracias de larga escala e que, no rastro desse debate, se insere a discussão sobre

\footnotetext{
${ }^{5}$ De fato, até 1998 , as redes municipais de ensino organizavam a matrícula de seus alunos independentemente da rede estadual. Essa dessincronia acarretou, muitas vezes, a superlotação de uma rede em detrimento da outra, comprometendo a otimização dos equipamentos públicos. Além disso, como as matrículas eram feitas na segunda quinzena de novembro - com o início das aulas em fevereiro -, as inesperadas demandas de vagas em determinados locais não podiam ser atendidas porque não havia tempo suficiente para novas contruções e/ou ampliação da escolas. A antecipação do cadastro feito em conjunto por ambas as esferas executivas - processo esse mediado pela UNDIME -, facilitou e otimizou o atendimento da demanda.
} 
a necessidade de ampliação da participação dos atores envolvidos na operacionalização das políticas sociais, em nível local. De fato, de acordo com esse princípio político, o processo de municipalização em curso parece facilitar a superação dos problemas colocados pelos diferentes níveis da burocracia, bem como para o desenvolvimento de experiências alternativas, delimitadas territorialmente e beneficiadas pela proximidade do poder. Esta dinâmica aperfeiçoa a complementariedade necessária entre os diferentes níveis de escala dentro do regime democrático. De outro lado, no entanto, os limites e a complexidade dessa engenharia institucional parecem colocar em risco os mecanismos estabilizadores da própria gestão do sistema, pois esta vem sendo redefinida na base da negociação nem sempre favorável para o poder local. Para que o novo desenho não expresse apenas a reconfiguração de novas práticas discursivas oficiais a partir de velhos modelos de exercício da democracia e da gestão das políticas que lhes dão materialização, o processo em curso até poderia consolidar o caminho de aprendizagem institucional recém iniciado para ambas as esferas, desde que levasse em consideração as peculiaridades locais e os diferentes estágios da cultura política que permeiam a vida desses municípios.

\section{REFERÊNCIAS BILIOGRÁFICAS}

MARTINS, A. M. (coord.) O Processo de municipalização no Estado de São Paulo: mudanças institucionais e atores escolares. São Paulo: Fundação Carlos Chagas/FAPESP. Relatório Final. 2002.

SANTOS, Boaventura de S., (org.), Democratizar a democracia. Rio de Janeiro: Civilização Brasileira, 2002.

SÃo PAULO (Estado) Secretaria da Educação. Decreto 40.673, de 16.01.96. Institui o Programa de Ação de Parceria Educacional Estado/Município para atendimento ao ensino fundamental. São Paulo: SEE, 1996. v. XLI.

SÃo PAULO (Estado) Secretaria da Educação. A Municipalização do Ensino Fundamental: o sucesso e o processo. São Paulo: 2002. 